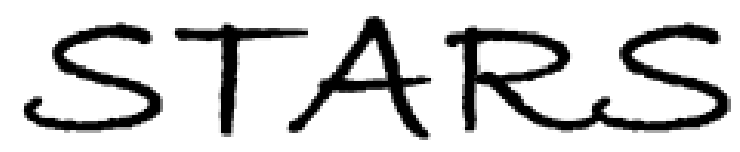

University of Central Florida

STARS

$1-1-2013$

\title{
On electric conduction of amorphous silicon carbonitride derived from a polymeric precursor
}

Yaohan Chen

University of Central Florida

Fuqian Yang

Linan An

University of Central Florida

Find similar works at: https://stars.library.ucf.edu/facultybib2010

University of Central Florida Libraries http://library.ucf.edu

This Article is brought to you for free and open access by the Faculty Bibliography at STARS. It has been accepted for inclusion in Faculty Bibliography 2010 s by an authorized administrator of STARS. For more information, please contact STARS@ucf.edu.

\section{Recommended Citation}

Chen, Yaohan; Yang, Fuqian; and An, Linan, "On electric conduction of amorphous silicon carbonitride derived from a polymeric precursor" (2013). Faculty Bibliography 2010s. 3799.

https://stars.library.ucf.edu/facultybib2010/3799

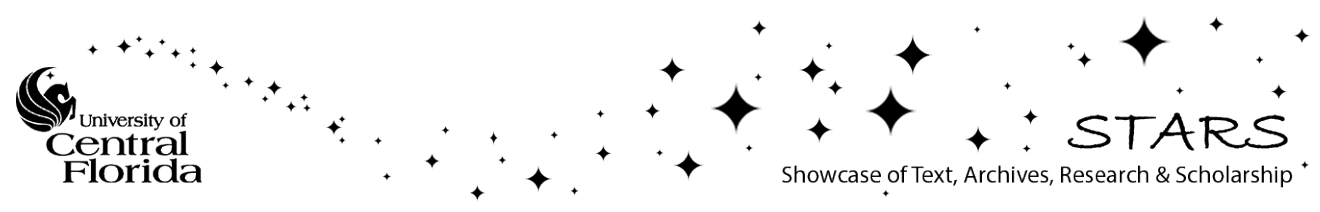




\section{On electric conduction of amorphous silicon carbonitride derived from a polymeric precursor}

Cite as: Appl. Phys. Lett. 102, 231902 (2013); https://doi.org/10.1063/1.4809825

Submitted: 12 April 2013 . Accepted: 23 May 2013 . Published Online: 11 June 2013

Yaohan Chen, Fuqian Yang, and Linan An
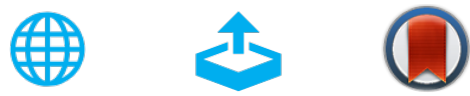

View Online

Export Citation

CrossMark

\section{ARTICLES YOU MAY BE INTERESTED IN}

On electronic structure of polymer-derived amorphous silicon carbide ceramics

Applied Physics Letters 104, 221902 (2014); https://doi.org/10.1063/1.4881139

Silicoboron-carbonitride ceramics: A class of high-temperature, dopable electronic materials Applied Physics Letters 78, 3076 (2001); https://doi.org/10.1063/1.1370540

Wireless passive polymer-derived SiCN ceramic sensor with integrated resonator/antenna Applied Physics Letters 103, 163505 (2013); https://doi.org/10.1063/1.4824827

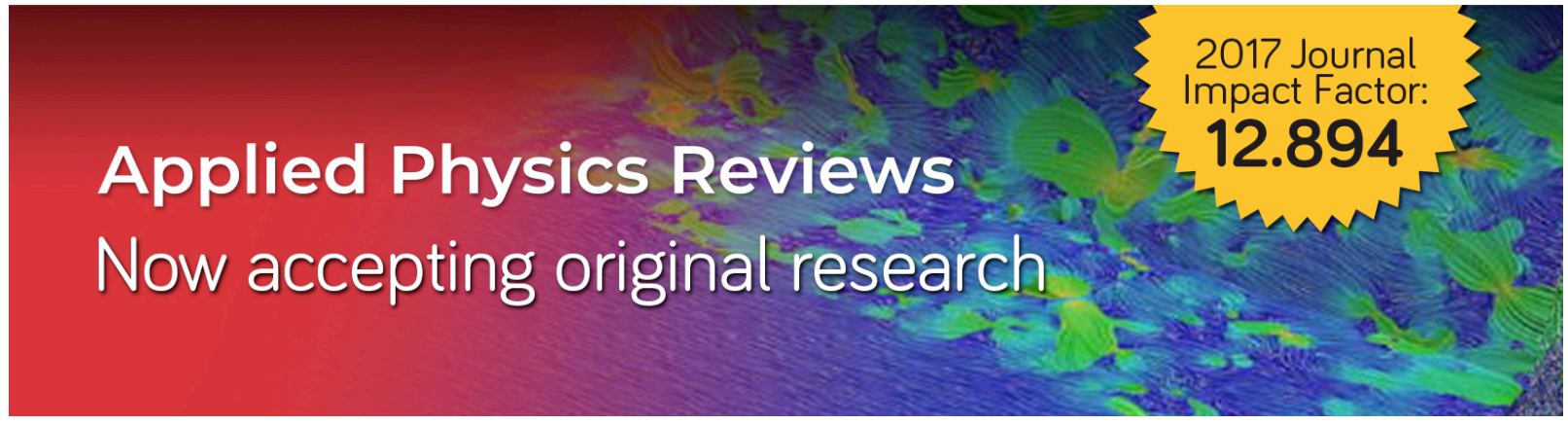




\title{
On electric conduction of amorphous silicon carbonitride derived from a polymeric precursor
}

\author{
Yaohan Chen, ${ }^{1}$ Fuqian Yang, ${ }^{2}$ and Linan $\mathrm{An}^{1, \mathrm{a})}$ \\ ${ }^{1}$ Department of Materials Science and Engineering and Advanced Materials Processing and Analysis Center, \\ University of Central Florida, Orlando, Florida 32816, USA \\ ${ }^{2}$ Department of Chemical and Materials Engineering, University of Kentucky, Lexington, Kentucky 40506 , \\ USA
}

(Received 12 April 2013; accepted 23 May 2013; published online 11 June 2013)

\begin{abstract}
A long-existing problem that the conductivity of amorphous silicon carbonitrides derived from polymeric precursor increases significantly with pyrolysis temperature is investigated. We show that the conductivity exhibited an Arrhenius dependence on pyrolysis temperature, with the activation energy of $\sim 3.41 \mathrm{eV}$. Structural analysis using Raman spectroscopy reveals that the free carbon within the material undergoes a $s p^{3}$-to-s $s p^{2}$ transition as pyrolysis temperature increases, with the activation energy of $\sim 3.6 \mathrm{eV}$. We conclude that the pyrolysis-temperature induced increase in the conductivity is mainly due to the increase in the conductivity of the free carbon. A simple model is proposed to correlate the two. C 2013 AIP Publishing LLC. [http://dx.doi.org/10.1063/1.4809825]
\end{abstract}

Electronic behavior of amorphous silicon carbonitrides ( $\mathrm{SiCNs}$ ) synthesized by thermal decomposition of polymeric precursors (named polymer-derived ceramics, PDCs) has attracted tremendous interest in the past decade. ${ }^{1,2}$ The driving forces for such interest are that the materials provide a unique model system for studying the conduction behavior of complex amorphous covalent materials, and the materials are very promising for making micro-sensors and microelectromechanical systems (MEMS) for applications in harsh environmental. $^{3,4}$ Unlike conventional polycrystalline ceramics made by sintering corresponding powders or amorphous films made by chemical/physical depositions, polymer-derived SiCNs possess a unique structure which combines an amorphous network composed of a mixture of various $\mathrm{SiC}_{\mathrm{x}} \mathrm{N}_{\mathrm{y}}(\mathrm{x}+\mathrm{y}=4)$ tetrahedra, named amorphous SiCN phase; and nano-sized, highly disordered, graphite-like carbon, named "free-carbon" phase. ${ }^{1}$ This unique structure confers PDCs a set of unique electric properties, such as well-behaved high-temperature semiconducting behavior up to $1300{ }^{\circ} \mathrm{C},{ }^{5,6}$ anomalously high piezoresistivity, ${ }^{7}$ and profound doping effect. ${ }^{8,9}$ Previous studies revealed that the conduction mechanisms of PDCs depend on the concentration and/or morphology of the free-carbon phase, which has higher conductivity than the amorphous SiCN phase. For the materials where the free-carbon phase forms a percolation network, the conductivity of the ceramics is similar to that of glassy carbon. ${ }^{10}$ On the other hand, for materials where the free-carbon phase does not form the percolation network, there are two conduction mechanisms: ${ }^{11}$ tunnelingpercolation mechanism, when the free-carbon concentration is higher than a threshold; or a semiconducting mechanism controlled by the amorphous phase when the free-carbon concentration is lower than the threshold.

Despite these extensive efforts, one phenomenon about the conduction of PDCs has not been well understood. This is that the conductivity of PDCs can increase by 3-4 orders

\footnotetext{
${ }^{\text {a) }}$ Author to whom correspondence should be addressed. Electronic mail: linan.an@ucf.edu
}

of magnitude with increasing pyrolysis temperatures. ${ }^{1,2,12}$ Previously, it was assumed that such an increase in the conductivity was due to the increase in the conductivity of the free-carbon phase. However, this assumption is not based on any solid evidence; rather it is based on the observation of the concurrency of the increase in the conductivity and the $s p^{3}-s p^{2}$ transition during post-pyrolysis annealing. While the explanation is reasonable for the PDCs with the free-carbon percolation network, it is not clear how it will be valid for materials where the free carbon does not form the percolation network. In particular, we have demonstrated that for materials with low free-carbon concentrations, the conductivity was controlled by the matrix phase and exhibited amorphous semiconducting behavior. ${ }^{11}$ There are two questions need to be addressed to clarify the situation for PDCs with low free carbon: (i) is the pyrolysis-temperature induced conductivity change still primarily due to the change in the conductivity of the free carbon? and (ii) how does the change in the conductivity of the free carbon affect the overall conductivity of the PDC?

In this study, we investigate this phenomenon by studying the conductivity and structures as a function of pyrolysis temperature for a low free-carbon amorphous SiCN ceramic. We show that the room-temperature conductivity of the material exhibits an Arrhenius dependence on pyrolysis temperature. The activation energy of the Arrhenius dependence is similar to that for the $s p^{3}-s p^{2}$ transition of the free-carbon phase. As a result, we deduce that the increase in the conductivity of the material is due to the increase in the conductivity of the free-carbon phase. We then propose a simple model to account for the relation between the conductivity of the free carbon and that of the SiCN ceramic.

The amorphous SiCN studied here was synthesized by using a commercially available polysilazane (HTT1800, Kion Corp., Columbus, $\mathrm{OH}$ ) as the precursor. The detailed synthesis procedure was reported in Ref. 11. In brief, the obtained precursor was first cross-linked by heat-treatment at $350{ }^{\circ} \mathrm{C}$ for $4 \mathrm{~h}$ without any additive, and then ground to powder of $\sim 1 \mu \mathrm{m}$. The powder was pressed into disks of $10 \mathrm{~mm}$ 
TABLE I. Conductivity of samples pyrolyzed at different temperatures.

\begin{tabular}{lccccc}
\hline \hline Pyrolysis temperature $\left({ }^{\circ} \mathrm{C}\right)$ & 1000 & 1100 & 1200 & 1300 & 1350 \\
\hline Conductivity $(\mathrm{S} / \mathrm{cm})$ & $2.06 \times 10^{-9}$ & $1.46 \times 10^{-8}$ & $1.21 \times 10^{-7}$ & $7.46 \times 10^{-7}$ & $1.50 \times 10^{-6}$ \\
\hline \hline
\end{tabular}

diameter. The obtained disks were pyrolyzed in a tube furnace at temperatures of $1000,1100,1200,1300$, and $1350{ }^{\circ} \mathrm{C}$ for $4 \mathrm{~h}$, respectively. The entire synthesis and pyrolysis processes were performed in flowing, ultra-high-purity argon to minimize possible oxygen contamination. The resulted samples were first analyzed using X-ray diffraction (XRD) to confirm that they were still amorphous without detectable crystalline phase. Our previous study revealed that the freecarbon concentration of SiCNs obtained this way was lower than the tunneling-percolation threshold; thus, the conduction of the materials should have been dominated by the matrix phase. $^{11}$

The conductivity of the samples was obtained by measuring their I-V curves on KEITHLEY 2400 (Keithley Instruments, Inc., Cleveland, OH). First, the obtained specimens of $\sim 1 \mathrm{~mm}$ in thickness were polished to $1 \mu \mathrm{m}$ finish. Silver paste was then painted on the surfaces of the samples as the electrodes. The obtained conductivity is listed in Table I. It shows that the conductivity of the $\mathrm{SiCN}$ increases by 3 orders of magnitude when pyrolysis temperature increases from 1000 to $1350^{\circ} \mathrm{C}$. In order for further analysis of the data, we plot the conductivity as a function of pyrolysis temperature (Fig. 1). It is interesting to see that the conductivity exhibits Arrhenius dependence with respect to the pyrolysis temperature. The apparent activation energy calculated from the curve in Fig. 1 is $3.41 \mathrm{eV}$. We find that this value is similar to that for $s p^{3}-s p^{2}$ transition in amorphous carbon, which is between 3.3 and $3.6 \mathrm{eV} .{ }^{13-15}$ The similar activation energy motivated us to think that the two phenomena could result from the same process; that is to say that the pyrolysis temperature induced increase in the conductivity of the $\mathrm{SiCN}$ could be due to the increase in the conductivity of its free-carbon phase.

In order to clarify this, we characterized the structure of the free carbon in the materials using Raman spectroscopy. Fig. 2 shows typical Raman spectra of the materials

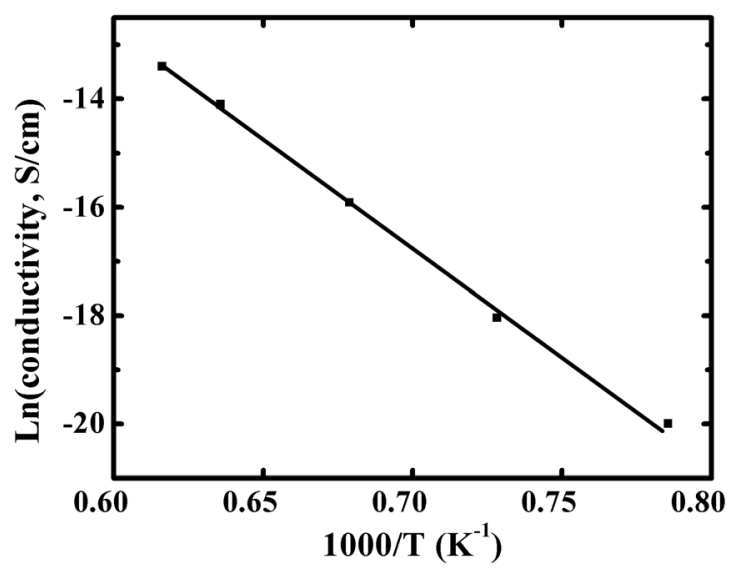

FIG. 1. Conductivity of polymer-derived $\mathrm{SiCN}$ as a function of pyrolysis temperature in an Arrhenius plot. pyrolyzed at different temperatures. The spectra show typical features of free carbon in polymer-derived ceramics: a $D$ peak at $\sim 1350 \mathrm{~cm}^{-1}$ resulted from the breathing modes of $s p^{2}$ carbon atoms in rings and a $G$ peak at $\sim 1600 \mathrm{~cm}^{-1}$ stemmed from in-plane bond stretching of $s p^{2}$ carbon. ${ }^{16-20} \mathrm{It}$ can be seen that the peak intensity ratio of $D$-to-G increases with increasing pyrolysis temperature, both peaks become sharper. In addition to the $\mathrm{D}$ and $\mathrm{G}$ peaks, there is a small shoulder can be seen from the spectra at $\sim 1200 \mathrm{~cm}^{-1}$, which is due to the $s p^{2}-s p^{3}$ bonds stretching vibration (named D4). ${ }^{19}$ It is seen that the intensity of this peak decreases with increasing pyrolysis temperature and disappears at temperatures above $1200^{\circ} \mathrm{C}$. These results suggest that the freecarbon phase in the SiCN transitioned from amorphous carbon towards nanocrystalline graphite with increasing pyrolysis temperature. ${ }^{16,18}$

According to Ferrari and co-workers, ${ }^{13}$ the activation energy of the graphitization of amorphous carbon can be calculated using following equation:

$$
E=K T_{c} \ln (\nu \tau),
$$

where $K$ is Boltzmann constant, $\nu$ is the phonon frequency of carbon which is $\sim 5 \times 10^{13}, \tau$ is a constant about $\sim 1 \mathrm{~s}$, and $T_{c}$ is a characteristic temperature where the structure of the amorphous carbon exhibits a sudden change. They determined the $T_{c}$ for a tetrahedral amorphous carbon and calculated that the activation energy of the $s p^{3}-s p^{2}$ transition in the amorphous carbon was about $3.3 \mathrm{eV} .{ }^{13,14}$ Using the same principle, Grierson et al. ${ }^{15}$ measured the activation energy of the $s p^{3}-s p^{2}$ transition for an amorphous carbon by determining the sudden change in the structure using near-edge $\mathrm{x}$-ray absorption fine structure (NEXAFS). They reported that the activation energy is $3.5 \pm 0.9 \mathrm{eV}$ for the amorphous carbon.

In order to abstract the structural information, the Raman spectra in Fig. 2 were curve-fitted using Lorentzian

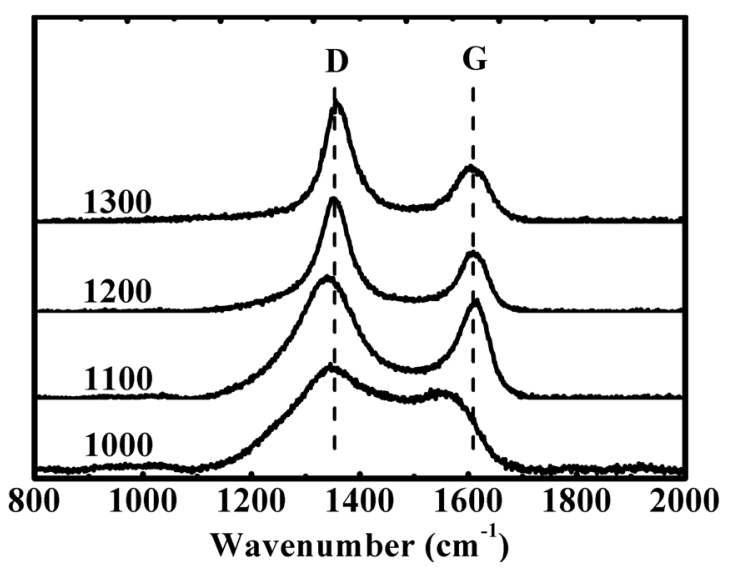

FIG. 2. Raman spectra of polymer-derived SiCN ceramics pyrolyzed at different temperatures. 
function for D-peak and Breit-Wigner-Fano function $(B W F)^{21}$ for G-peaks. The BWF line shape is given by

$$
I(\omega)=\frac{I_{0}\left[1+2\left(\omega-\omega_{0}\right) / Q \Gamma\right]^{2}}{1+\left[2\left(\omega-\omega_{0}\right) / \Gamma\right]^{2}},
$$

where $I_{0}$ is the peak intensity, $\omega_{0}$ is the peak position, $\Gamma$ is the full width at half maximum (FWHM), and $Q^{-1}$ is the BWF coupling coefficient. Fig. 3 plots the G-peak position and FWHM of the free-carbon as a function of pyrolysis temperature. The position of G-peak moving to a higher wave number and the decrease in FWHM confirm that the free carbon transitions from amorphous to nanocrystalline graphite. The figure reveals that both of them show sudden change between 1000 and $1100^{\circ} \mathrm{C}$. Consequently, we select $1050^{\circ} \mathrm{C}$ as the characteristic temperature for the current material. The activation energy for the $s p^{3}-s p^{2}$ transition of the free-carbon was thereby calculated to be $\sim 3.60 \mathrm{eV}$. This value is very close to that measured for the conduction change, suggesting that the increase in the conductivity of the $\mathrm{SiCN}$ with pyrolysis temperature is likely due to the increase in carbon conductivity caused by the $s p^{3}-s p^{2}$ transition.

Now, we would like to correlate the change in the conductivity of the free carbon affecting the overall conductivity of a PDC with a low free-carbon concentration where no percolation (or tunneling-percolation) is formed. The conductivity of a composite composed of a relatively low-conductive matrix and high-conductive dispersed particles was first
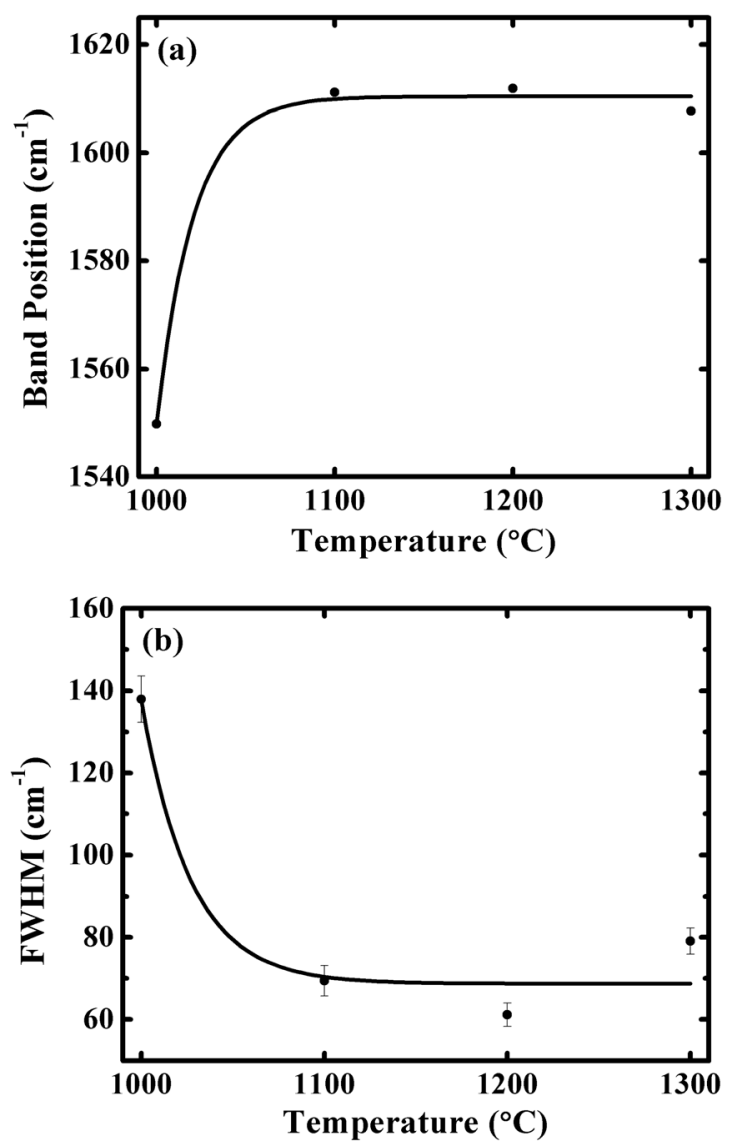

FIG. 3. The position (a) and FHWM (b) of the G-peak as a function of pyrolysis temperature. treated by Maxwell. ${ }^{22}$ Maxwell's original model was only applicable to the situation where the conductive particle is infinitely dilute. Later on, several models had been developed for systems containing high conductive particle concentrations, based on the same assumption as Maxwell. ${ }^{23-25}$ The common problem of these models is that they do not consider the interaction between the particles. Recently, studies $^{26}$ on carbon nanotube (CNT) reinforced cement materials have clearly demonstrated that there is a strong electric field concentration between the conducting CNTs when they are approaching each other.

Hereby, we propose that there is a strong electric field concentration between the conducting free-carbon particles in our SiCN (Fig. 4). Such field concentration is due to the high conductivity and small size of the free carbon, as well as the short distance between them. The field concentration causes the field applied on the matrix ligament between the free carbon particles to be much higher than the external field applied. As a result, the overall current pass through the material is higher than it should be. Thereby, the "apparent" conductivity of the material is higher than it should be when there is no field concentration. This phenomenon is similar to the stress concentration due to the presence of a hole in an elastic plate. The field concentration increases with the increase in the conductivity of the free carbon. Such field concentration should make matrix-particle-matrix, instead of matrix only, as the main current path, as shown in Fig. 4, which is consistent with the complex impedance measurements on similar materials. ${ }^{27}$

In summary, we studied the effect of pyrolysis temperature on the conductivity of a low free-carbon amorphous silicon carbonitride prepared by thermal decomposition of a polymeric precursor. It was found that the conductivity of the material increased by 3 orders of magnitude when pyrolysis temperature increased from 1000 to $1350{ }^{\circ} \mathrm{C}$. More interestingly, the conductivity exhibited Arrhenius dependence on the pyrolysis temperature. The "apparent" activation energy was calculated from the Arrhenius plot to be $3.41 \mathrm{eV}$. We then characterized the microstructure of the materials using Raman spectroscopy. The results showed that the freecarbon phase underwent a $s p^{3}-s p^{2}$ transition with increasing pyrolysis temperature, with similar activation energy. We, thereby, believe that the increase in the conductivity of the material is due to the increase in the conductivity of its free

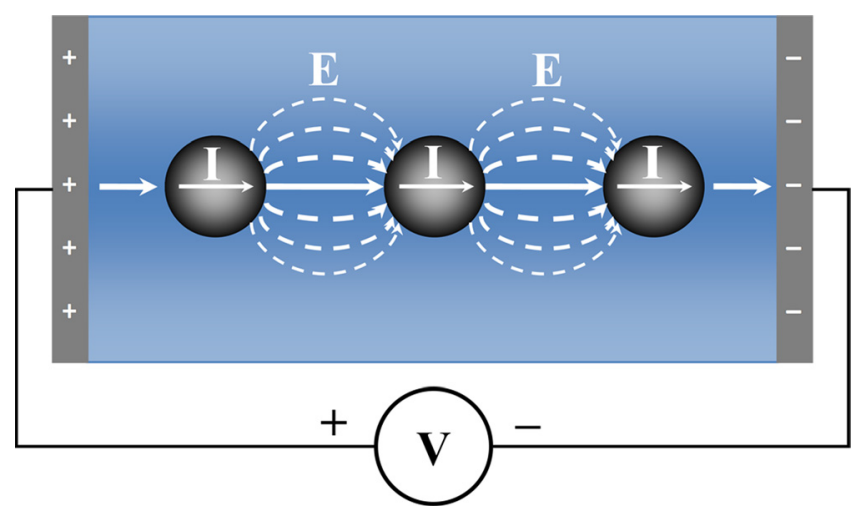

FIG. 4. Schematic illustration of the proposed electric field concentration and current path in the SiCN ceramics. 
carbon phase. We then proposed a simple model based on electric field concentration to explain the phenomenon.

This work was financially supported by National Energy Technology Laboratory, Department of Energy of USA (DEFE0007004).

${ }^{1}$ P. Colombo, G. Mera, R. Riedel, and G. D. Sorarù, J. Am. Ceram. Soc. 93(7), 1805 (2010).

${ }^{2}$ P. Colombo, R. Riedel, G. D. Sorarù, and H.-J. Kleebe, Polymer Derived Ceramics: From Nano-Structure to Applications (DEStech Publications, Lancaster, PA, 2010).

${ }^{3}$ Y. Liu, L. Liew, R. Lou, L. An, V. M. Bright, M. L. Dunn, J. W. Daily, and R. Raj, Sens. Actuators A 95(2-3), 143 (2002).

${ }^{4}$ L. Liew, W. Zhang, L. An, S. Shah, R. Lou, Y. Liu, T. Cross, K. Anseth, V. Bright, and R. Raj, Am. Ceram. Soc. Bull. 80(5), 25 (2001).

${ }^{5}$ Y. Wang, T. Jiang, L. Zhang, and L. An, J. Am. Ceram. Soc. 92(7), 1603 (2009).

${ }^{6}$ H. Ryu, Q. Wang, and R. Raj, J. Am. Ceram. Soc. 93(6), 1668 (2010).

${ }^{7}$ L. Zhang, Y. Wang, Y. Wei, W. Xu, D. Fang, L. Zhai, K. Lin, and L. An, J. Am. Ceram. Soc. 91(4), 1346 (2008).

${ }^{8}$ P. A. Ramakrishnan, Y. T. Wang, D. Balzar, L. An, C. Haluschka, R. Riedel, and A. Herman, Appl. Phys. Lett. 78(20), 3076 (2001).

${ }^{9}$ A. M. Hermann, Y. T. Wang, P. A. Ramakrishnan, D. Balzar, L. An, C. Haluschka, and R. Riedel, J. Am. Ceram. Soc. 84(10), 2260 (2001).

${ }^{10}$ S. Trassl, M. Puchinger, E. Rossler, and G. Ziegler, J. Eur. Ceram. Soc. 23, 781 (2003).
${ }^{11}$ Y. Wang, L. Zhang, W. Xu, T. Jiang, Y. Fan, D. Jiang, and L. An, J. Am. Ceram. Soc. 91(12), 3971 (2008).

${ }^{12}$ C. Haluschka, C. Engel, and R. Riedel, J. Eur. Ceram. Soc. 20, 1365 (2000).

${ }^{13}$ A. C. Ferrari, S. E. Rodil, J. Robertson, and W. I. Milne, Diam. Relat. Mater. 11(3-6), 994 (2002).

${ }^{14}$ A. C. Ferrari, B. Kleinsorge, N. A. Morrison, A. Hart, V. Stolojan, and J. Robertson, J. Appl. Phys. 85(10), 7191 (1999).

${ }^{15}$ D. S. Grierson, A. V. Sumant, A. R. Konicek, T. A. Friedmann, J. P. Sullivan, and R. W. Carpick, J. Appl. Phys. 107, 033523 (2010).

${ }^{16}$ E. H. Martins Ferreira, M. V. O. Moutinho, F. Stavale, M. M. Lucchese, R. B. Capaz, C. A. Achete, and A. Jorio, Phys. Rev. B 82(12), 125429 (2010).

${ }^{17}$ F. Tuinstra and J. L. Koenig, J. Chem. Phys. 53(3), 1126 (1970).

${ }^{18}$ A. C. Ferrari and J. Robertson, Phys. Rev. B 61(20), 14095 (2000).

${ }^{19}$ A. Sadezky, H. Muckenhuber, H. Grothe, R. Niessner, and U. Pöschl, Carbon 43(8), 1731 (2005).

${ }^{20}$ A. C. Ferrari and J. Robertson, Phys. Rev. B 64(7), 075414 (2001).

${ }^{21}$ M. V. Klein, in Light Scattering in Solids III, edited by M. Cardona and G. Guntherodt, Topics in Applied Physics, Vol. 51 (Springer-Verlag, Berlin, 1982)

${ }^{22}$ J. C. Maxwell, A Treatise on Electricity and Magnetism, 2nd ed. (Clarendon Press, Oxford, 1881), Vol. 1, 435 pp.

${ }^{23}$ K. W. Wagnar, Arch Elektrotech. (Berlin) 2, 371 (1914).

${ }^{24}$ D. A. G. Bruggeman, Ann. Phys. (Leipzig) 416(7), 636 (1935).

${ }^{25}$ R. Pal, J. Compos. Mater. 41(20), 2499 (2007).

${ }^{26}$ L. Woo, S. Wansom, A. D. Hixson, M. A. Campo, and T. O. Mason, J. Mater. Sci. 38, 2265 (2003).

${ }^{27}$ K. Wang, B. Ma, Y. Wang, and L. An, "Complex impedance spectra of polymer-derived silicon oxycarbides," J. Am. Ceram. Soc. (to be published). 